\title{
HAZARD2 project : airspeed and temperature measurements in jet engine blast
}

\author{
T.Boisson thomas.boisson@airbus.com
}

\begin{abstract}
For ground airport operations, a dangerous area is defined behind the aircraft when engines are running. Measuring the temperature and airspeed in this area is needed to calibrate simulation models and adjust the danger area size to the real conditions. A heavy fixed on ground instrumentation was possible but an innovative solution has been chosen, based on Lidar technology for airspeed measurements and Bragg sensors on optical fibers for temperature measurements.
\end{abstract}

Key words: Jet engine blast, temperature, bragg sensors, optical fiber, Lidar

\section{Airspeed and temperature measurements in jet engine blast :}

A classical instrumentation is to fix in the ground an heavy metal structure to attach the sensors. This solution has many inconveniences including the need to build concrete foundations to attach the structure, which is difficult task in an airport area. This metal structure $(3 \mathrm{~m}$ height, $35 \mathrm{~m}$ long) would have to sustain airspeed up to $150 \mathrm{~m} / \mathrm{s}$. A huge number of sensor would be required with many wirings and acquisitions concerns. To obtain measurements in various distances from the aircraft, this one needs to be moved relatively to the sensor ramp :

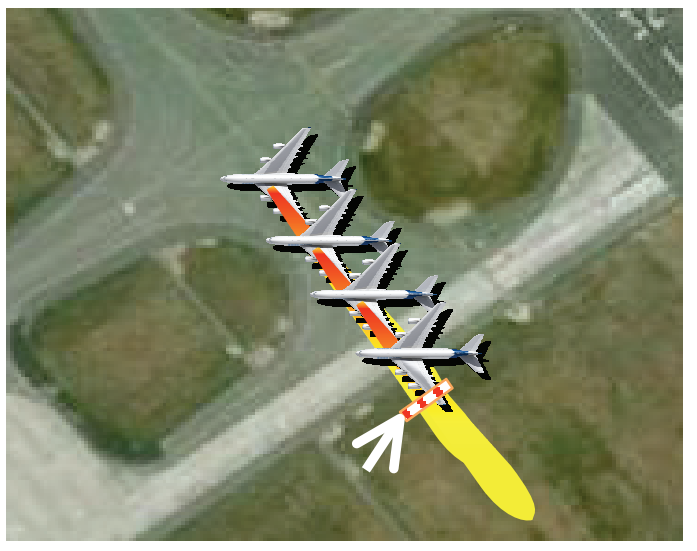

To avoid this kind of instrumentation, a better solution has been put in place : an adapted Lidar was used to measure airspeed and an instrumented cable (140m long) was moved around the aircraft in the jet blast zone to perform a kind of temperature scanning.

\section{Lidar solution for airspeed}

A meteorological Lidar Windcube200S was customized by the manufacturer (Leosphere) to cope with Airbus needs: long distance and low windspeeds (up to $10 \mathrm{~km}$ and $30 \mathrm{~m} / \mathrm{s}$ ) measurements to short distance and high airspeeds $(100 \mathrm{~m}$ minimum up to $1000 \mathrm{~m}$ and $60 \mathrm{~m} / \mathrm{s}+$ filtering for higher speeds).

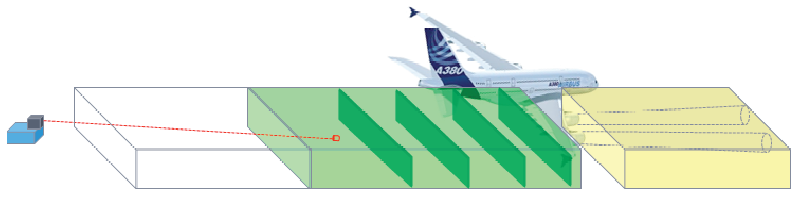

Classical instrumentation would have given airspeed datas only in the $X Y$ plan of the metalic structure carrying the sensors. Instead of that, Lidar with a motorized scanning head has provided unexpected quantity of datas in a full volume from the engine exhaust up to $150 \mathrm{~m}$ behind the aircraft.

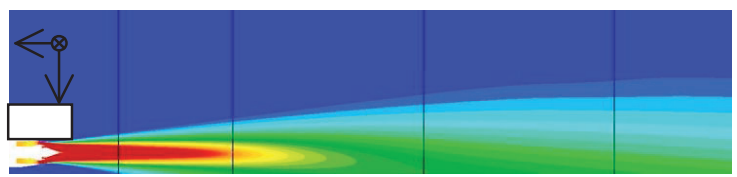

\section{Bragg sensors solution for temperatures}

For temperature measurements, a cable carrying optical fibers with Bragg sensors was moved around the aircraft to scan the temperature field. 
The measurement principle is based on a modification of the reflected wavelength of each sensor on the fiber depending of the temperature. Selecting different central wavelength for each sensors allows multiplexing many sensors on a single fiber. Bragg sensors were printed on 2 fibers, giving 20 sensors on the first $100 \mathrm{~m}$ of the instrumented cable. The optical fibers were protected by a thin inox tube, then they were fixed to a strong stainless steel cable. This cable was attached on one side to the aircraft body landing gear, and on the other side to a $0,7 t$ counterweight carried by a forklift.

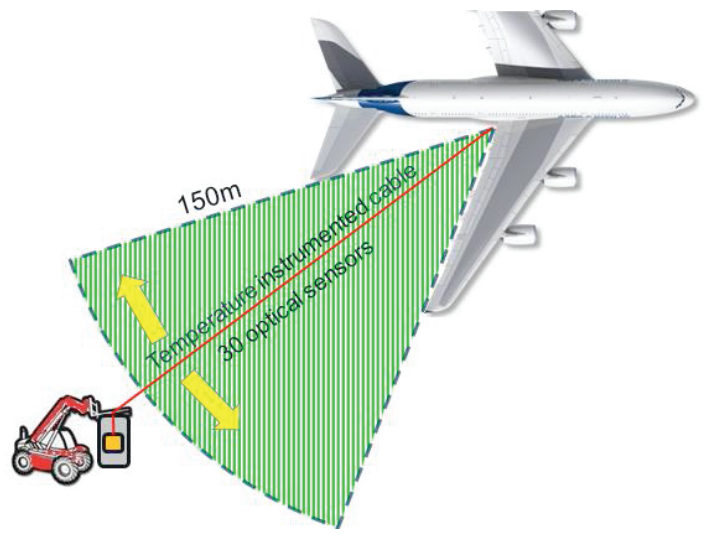

The cable max load of 4 tons was calculated to sustain both counterweight and jet induced drag.

Maintaining the counterweight in suspension, the forklift driver was able to perform semi circular trajectory around the aircraft. Temperatures were acquired by an optical interrogation unit FiberSensing FS2200, installed on traction counterweight mechanism. By matching time between the forklift trajectory and measures, a temperature mapping was obtained in the area where the cable was moved.

Several initial test were done to verify cable overload release mechanism to avoid forklift tumble and cable straightness regarding counterweight value and induced drag.

Results of this instrumentations are very interesting :

- removable instrumentations that can be used on various test zone

- instrumentation cost divided by 6

- quantity and quality of airspeed datas in a volume behind the aircraft instead of only $X Y$ plan values, allowing simulations models validations and more accurate danger areas definition to optimize airports operations. 